\section{Part 6. Pediatric advanced life support: 2015 Korean Guidelines for Cardiopulmonary Resuscitation}

\author{
Do Kyun Kim 1 , Won Kyoung Jhang ${ }^{2}$, Ji Yun Ahn ${ }^{3}$, Ji Sook Lee ${ }^{4}$, \\ Yoon Hee Kim${ }^{5}$, Bongjin Lee ${ }^{6}$, Gi Beom Kim ${ }^{6}$, Jin-Tae Kim ${ }^{7}$, June Huh ${ }^{8}$, \\ June Dong Park ${ }^{6}$, Sung Phil Chung ${ }^{9}$, Sung Oh Hwang ${ }^{10}$ \\ 'Department of Emergency Medicine, Seoul National University College of Medicine, Seoul, Korea \\ ${ }^{2}$ Department of Pediatrics, Ulsan University College of Medicine, Seoul, Korea \\ ${ }^{3}$ Department of Emergency Medicine, Hallym University College of Medicine, Seoul, Korea \\ ${ }^{4}$ Department of Emergency Medicine, Ajou University College of Medicine, Suwon, Korea \\ ${ }^{5}$ Department of Pediatrics, Yonsei University College of Medicine, Seoul, Korea \\ ${ }^{6}$ Department of Pediatrics, Seoul National University College of Medicine, Seoul, Korea \\ ${ }^{7}$ Department of Anesthesiology and Pain Medicine, Seoul National University College of Medicine, Seoul, \\ Korea \\ ${ }^{8}$ Department of Pediatrics, Sungkyunkwan University School of Medicine, Seoul, Korea \\ ${ }^{9}$ Department of Emergency Medicine, Yonsei Universtiy College of Medicine, Seoul, Korea \\ ${ }^{10}$ Department of Emergency Medicine, Yonsei University Wonju College of Medicine, Wonju, Korea
}

Asphyxial cardiac arrest is more common among children than in adults, and pediatric cardiac arrests result from gradual deterioration due to respiratory failure or sepsis rather than arrhythmic or structural disease itself.' Approximately 5\% to 15\% of all in-hospital and out-of-hospital pediatric cardiac arrests exhibit ventricular fibrillation (VF) or pulseless ventricular tachycardia (VT) at the time of diagnosis. ${ }^{2}$ Approximately 25\% of in-hospital cardiac arrests exhibit VF or pulseless $\mathrm{VT}$, and the frequency of these patterns increases with age. ${ }^{3}$ Therefore, it has been suggested that each hospital organize and maintain an acute response system or rapid response team to improve the treatment of in-hospital cardiac arrest. ${ }^{4}$

\section{BASIC LIFE SUPPORT CONSIDERATIONS FOR PEDIATRIC ADVANCED LIFE SUPPORT}

\section{Collaborative management using a team approach}

It is important to build an efficient team of healthcare professionals that provides advanced life support during cardiopulmonary resuscitation (CPR). The following factors are important in order for these teams to effectively perform CPR: Chest compressions should be performed immediately after the need for CPR has been established, and ventilation should be performed if there is a second rescuer. Breathing is also important for infants or children, and compression-ventilation CPR, rather than compression-only CPR, should be performed inside hospitals. Although the preparation of a ventilation device can delay effective ventilation in some cases, chest compressions should be performed immediately for both infants and children. High-quality CPR is critical to successful pediatric advanced life support (PALS), and is defined as starting CPR within $10 \mathrm{sec}-$ onds after identifying the cardiac arrest, an adequate compression rate, an adequate compression depth, complete recoil of the chest wall, minimal interruptions in the compressions, a sufficient
elSSN: $2383-4625$

Received: 16 February 2016

Revised: 19 March 2016

Accepted: 19 March 2016

Correspondence to: June Dong Park Department of Pediatrics, Seoul National University College of Medicine, 101 Daehak-ro, Jongno-gu, Seoul 03080, Korea

E-mail:jdparkmd@snu.ac.kr



How to cite this article:

Kim DK, Jhang WK, Ahn JY, Lee JS, Kim YH, Lee B, Kim GB, Kim JT, Huh J, Park JD, Chung SP, Hwang SO. Part 6. Pediatric advanced life support: 2015 Korean Guidelines for Cardiopulmonary Resuscitation. Clin Exp Emerg Med 2016;3(S):S48-S61.

This is an Open Access article distributed under the terms of the Creative Commons Attribution Non-Commercial License (http:// creativecommons.org/licenses/by-nc/3.0/). 
chest expansion during the ventilation, and the avoidance of hyperventilation. If two rescuers are performing chest compressions and breathing, the third rescuer (if available) should prepare a monitor and defibrillator, establish the medication route(s), and calculate the medication dosage(s). When several rescuers perform $\mathrm{CPR}$, the rescuers should clearly communicate their roles using precise and respectful expressions.

\section{Patients on monitoring}

If the patient has an intra-arterial catheter, the adequacy of the compressions and the return of spontaneous circulation (ROSC) can be evaluated by observing the pressure waveform. Capnography is also useful for evaluating the adequacy of the compressions and identifying ROSC.

\section{Respiratory failure}

Respiratory failure is a condition that indicates inadequate oxygenation and/or ventilation, and should be suspected if the following symptoms are observed.

- An increasing respiratory rate and signs of respiratory failure (e.g., nasal flaring, seesaw respirations, and moaning sounds)

- An inadequate respiratory rate and respiratory effort, thoracic movement, reduced breath sounds, or breathlessness in patients with a reduced level of consciousness

- Cyanosis while an external oxygen supply is being provided

\section{Shock}

Hypotension does not develop during the early phase of shock, which is also called compensated shock or normal pressure shock. Compensated shock presents as tachycardia, cool and pale extremities, a $>2$ seconds delay in the capillary refill time, a weak peripheral pulse with a maintained central pulse, and a normal blood pressure. If the compensation mechanisms fail, it can result in hypoperfusion of the major organs, reduced consciousness, reduced urine output, metabolic acidosis, tachypnea, weak central pulses, and a change in skin color.

Cardiac output is the product of heart rate and stroke volume. If the stroke volume is decreased due to any cause, the heart rate increases to compensate for the decrease in cardiac output. Sustained sinus tachycardia without other causes can be the first sign of shock, although bradycardia can develop after shock has progressed. Reductions in cardiac output and poor perfusion can decrease the peripheral pressure (intensity or quality), prolong the capillary refill time, and lower the skin temperature despite a warm surrounding temperature. However, the blood vessels of the skin and muscles are inadequately dilated during early septic shock, and the patient may exhibit a palpable peripheral pulse and rela- tively high skin temperature, despite being in shock.

The criteria for hypotension in infants and children during CPR are:

- Full-term infants (0 to 28 days old): a systolic pressure of $<60$ $\mathrm{mmHg}$

- Infants (1 to 12 months old): a systolic pressure of $<70 \mathrm{mmHg}$

- Children (1 to 10 years old): a systolic pressure of less than (70+ [ $2 \times$ age in years] $) \mathrm{mmHg}$

- Children ( $>10$ years old): a systolic pressure of $<90 \mathrm{mmHg}$

These blood pressure criteria are below the fifth percentiles for the age-specific systolic pressures, and rarely occur in normal children.

\section{ADVANCED AIRWAY}

\section{Bag-mask ventilation}

Bag-mask ventilation is relatively effective and safe in cases of out-of-hospital CPR, compared to endotracheal intubation. ${ }^{5}$ Select an adequate size of mask, open the airway properly, completely attach the mask to the face, and maintain a sufficient respiratory rate and pressure to ensure that the chest rises properly. Hyperventilation can reduce blood flow to the brain and heart, as it increases intrathoracic pressure, reduces venous return, and reduces cardiac output. ${ }^{6}$ In addition, hyperventilation can cause air trapping in patients with peripheral airway collapse and barotrauma. Excessive inspiratory pressure can cause gastric inflation, which can lead to reflux of the stomach contents and pulmonary aspiration. In infants and children without an inserted advanced airway, perform two breaths after every 30 compressions (or after every 15 compressions if there are two rescuers). Stop compressions during the breathing, which should be performed for approximately 1 second per breath. Breaths should be performed every 6 seconds (10 per minute) without interruption of the compressions if an advanced airway is inserted. Perform breathing only every 3 to 5 seconds ( 12 to 20 per minute) if ROSC is achieved but respiration is inadequate. The ventilation rate should be increased when the patient is young.

\section{Two-person bag-mask ventilation}

Perform two-person bag-mask ventilation when there are two rescuers. This technique is especially helpful when a patient has airway collapse or low pulmonary compliance, or when the rescuer cannot completely attach the bag to the patient's face. ${ }^{7}$ During two-person bag-mask ventilation, one rescuer holds the mask to the face while lifting the patient's chin with both hands, while the other rescuer compresses the bag. Both rescuers should frequently confirm that the patient's chest is expanding properly. 


\section{Endotracheal intubation}

Significant training is needed to successfully perform endotracheal intubation in infants and children, because they have a unique tracheal structure. Compared to adults, children's tongues are relatively large, their airways are more flexible, the tip of their epiglottis is located at a relatively high and anterior portion of the neck, and their airway is smaller.

\section{1) Size of the pediatric endotracheal tube}

Among children who weigh $<35 \mathrm{~kg}$, even with a relatively short stature, determining the endotracheal tube (ETT)'s size based on height is more accurate than using their age (e.g., using a Broselow resuscitation tape). ${ }^{8,9}$ However, also prepare tubes that are 0.5 $\mathrm{mm}$ larger and smaller in internal diameter (ID) than the calculated tube size, regardless of the presence or absence of a cuff. If resistance is felt during the intubation, use the $0.5 \mathrm{~mm}$ smaller tube. If there is significant air leakage at the glottis, the $0.5 \mathrm{~mm}$ larger tube or a cuffed tube should be used. For an un-cuffed tube, use a tube with an ID of $3.5 \mathrm{~mm}$ for infants who are $<1$ year old, and a 4.0-mm tube for children who are 1 to 2 years old. For children who are $>2$ years old, use the following formula: ID of the uncuffed tube (in $\mathrm{mm}$ ) $=4+$ (age in years/4). If a cuffed tube must be used in an emergency, use a tube with an ID of $3.0 \mathrm{~mm}$ for children who are $<1$ year old, and a $3.5 \mathrm{~mm}$ tube for children who are 1 to 2 years old. For children who are $>2$ years old, use the following formula: ${ }^{10-13} \mathrm{ID}$ of the cuffed tube (in $\mathrm{mm}$ ) $=3.5+$ (age in years/4).

\section{2) Cuffed ETT}

Both cuffed and un-cuffed tubes can be used for endotracheal intubation in infants and children. If a cuffed tube is used during surgery, the frequency of reintubation can be reduced without an increased risk of complications. ${ }^{10}$ Using a cuffed tube in the intensive care unit (ICU) can reduce the risk of aspiration. ${ }^{14}$ If a cuffed tube is used, the cuff's pressure should be constantly monitored and the manufacturer's recommended pressure should be maintained (usually $<20$ to $25 \mathrm{cmH}_{2} 0$ ). A cuffed tube can be more effective if it is selected based on the size, location, and pressure of the cuff in cases with low pulmonary compliance, high airway resistance, or significant air leakage at the glottic area. ${ }^{15,16}$

\section{3) Endotracheal intubation}

Prepare a suction catheter, bag-mask, oxygen, and stylet before the intubation. The tip of the stylet should not pass the tip of the tube. Applying a water-based lubricant or sterile distilled water to the tip of the stylet may make it easier to remove after the intubation. Also prepare a functioning laryngoscope handle, blades, an extra light bulb, extra batteries, capnometry, tape to fix the tube, and gauze to clean the patient's face.

Perform endotracheal intubation after oxygen administration unless the patient is in cardiac arrest. Assisted ventilation can be performed if the patient's respiratory effort is insufficient. It should be performed with the preparation of a secondary method for maintaining the airway, in anticipation of intubation failure. Immobilize the cervical vertebrae to prevent spinal injury during the intubation in cases that involve severe trauma to the head, neck, or other areas. The procedure duration should not exceed $30 \mathrm{sec}-$ onds, as hypoxia or ischemic injury can occur due to inadequate or delayed intubation. Monitor the patient's heart rate and oxygen saturation (using pulse oximetry) while performing endotracheal intubation. Stop the procedure and wait until the patient's condition improves, while providing oxygen using a bag-mask, if the patient develops bradycardia ( $<60 / \mathrm{min})$, a change in skin color or blood circulation status, or oxygen saturation below the normal level. In cases of pediatric cardiac arrest, the endotracheal intubation should not be delayed to set up pulse oximetry, which cannot function properly if the pulse is not palpable.

Use either straight or curved laryngoscope blades. Once the tip of a straight blade passes the epiglottis, place it at the entrance of the vocal cords, lift the base of the tongue, and swipe the blade anteriorly to lift the epiglottis. If a curved blade is used, anteriorly adjust the location of the tongue's base after the tip of the blade is placed in the epiglottic vallecula. At that point, the laryngoscope blade or handle should not be used as a lever, and direct pressure on the lips or gum should be avoided.

The glottis entrance should be exposed for ideal endotracheal intubation. To simplify the intubation in infants and children, align the pharynx by placing a pillow under the patient's head with the chin in the sniffing position. For infants or children who are $<2$ years old, it is acceptable to lay them flat without a pillow to perform intubation through the mouth.

The depth of the ETT intubation can be calculated using the following formula: intubation depth (in $\mathrm{cm}$ ) = the tube's ID (in $\mathrm{mm}) \times 3$. For children who are $>2$ years old, the formula is: intubation depth (in $\mathrm{cm})=($ the child's age in years $/ 2)+12$.

\section{4) Checking the tube's location}

The correct location of the tube cannot be verified using only clinical signs such as chest wall movement or vapor inside the tube. The tube's location should be checked immediately after intubation, re-fixing the tube, transfer, and patient movement. The signs of a correct tube location are:

- Movement of the bilateral chest wall and symmetrical breathing sounds in both lungs, and particularly in the axillary areas 
- The absence of gastric inflation sounds

- Appropriate end-tidal $\mathrm{CO}_{2}$ (end-tidal carbon dioxide, $\mathrm{ETCO}_{2}$ )

- Adequate oxygen saturation while perfusion is maintained. However, oxygen saturation can be maintained for approximately 3 minutes after hyperoxygenation despite poor ventilation

- Laryngoscopic evidence that the tube is placed between the vocal cords

- Chest radiography findings that confirm the tube is correctly located

For immobilization of the tube, the tube should be fixed in a neutral position to prevent the tube from sliding deeper if the patient's neck flexes, or sliding out if the patient's neck extends. ${ }^{17}$ If the patient's condition suddenly deteriorates while they are intubated, determine whether the tube is displaced or occluded, pneumothorax is present, or a mechanical error has occurred.

\section{5) Capnometry or capnography}

If possible, verify the location of the ETT using capnometry for all age groups and in all circumstances, including in the pre-hospital, emergency room, ICU, ward, operation room, or transfer settings. ${ }^{16-18}$ However, this method cannot detect whether a tube is placed in the right main bronchus, despite the appearance of color changes or the proper waveform. Because $\mathrm{ETCO}_{2}$ may not be detected during cardiac arrest, even if the tube is properly located, the tube's location must be checked using a laryngoscope.

- If the capnometry is contaminated by gastric contents or an acidic drug, the color persists as the acidic color and does not accurately reflect the ventilation

-When epinephrine is intravenously infused, pulmonary perfusion is temporarily reduced and the $\mathrm{ETCO}_{2}$ value can decrease below the critical value ${ }^{18}$

- If there is severe airway occlusion, such as moderate asthma or pulmonary edema, the exhalation of $\mathrm{CO}_{2}$ can decrease below the critical value ${ }^{19}$

- In cases with air leakage at the glottis region, the $\mathrm{CO}_{2}$ is diluted and may not be detected, due to the insufficient ventilation

\section{DRUGS THAT ARE USED FOR PALS (Table 1)}

\section{Adenosine}

Adenosine temporarily blocks atrioventricular (AV) node conduction and interrupts the re-entrant mechanism. The half-life of adenosine is very short, which gives it a broad safety range. Large doses should be administered through a peripheral vein compared to a central vein, although adenosine can be also administered intraosseously. Additional normal saline should be provided immediately after an intravenous (IV) infusion of adenosine to help the adenosine rapidly enter the central circulation.

Table 1. Drugs used in pediatric advanced life support

\begin{tabular}{|c|c|c|}
\hline Medication & Dose & Remarks \\
\hline Adenosine & $0.1 \mathrm{mg} / \mathrm{kg}$ (maximum $6 \mathrm{mg}$ ) & $\begin{array}{l}\text { Monitor ECG } \\
\text { Rapid IV/IO bolus with flush }\end{array}$ \\
\hline Amiodarone & $\begin{array}{l}5 \mathrm{mg} / \mathrm{kg} \text { IV/IO; may repeat twice up to } 15 \mathrm{mg} / \mathrm{kg} \\
\text { Maximum single dose } 300 \mathrm{mg}\end{array}$ & $\begin{array}{l}\text { Monitor ECG and blood pressure; adjust administration rate to urgency (IV } \\
\text { push during cardiac arrest, more slowly over } 20 \text { to } 60 \text { minutes with } \\
\text { perfusing rhythm). Expert consultation strongly recommended prior to } \\
\text { use when patient has a perfusing rhythm. Use caution when adminis- } \\
\text { tering with other drugs that prolong OT (obtain expert consultation) }\end{array}$ \\
\hline Atropine & $\begin{array}{l}0.02 \mathrm{mg} / \mathrm{kg} \mathrm{IV} / \mathrm{IO} \\
0.04 \text { to } 0.06 \mathrm{mg} / \mathrm{kg} \text { ET (flush with } 5 \mathrm{~mL} \text { of normal saline and follow with } \\
5 \text { ventilations.) } \\
\text { Maximum single dose: } 0.5 \mathrm{mg}\end{array}$ & Higher doses may be used with organophosphate poisoning \\
\hline Calcium chloride (10\%) & $20 \mathrm{mg} / \mathrm{kg} \mathrm{IV} / \mathrm{IO}$, Maximum dose $2 \mathrm{~g}$ & Administer slowly \\
\hline Epinephrine & 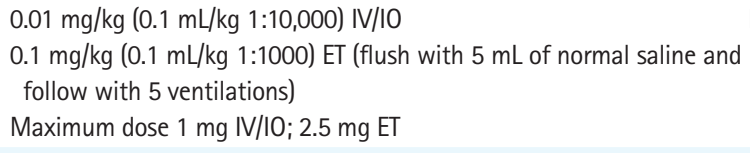 & May repeat every 3 to 5 minutes \\
\hline Glucose & 0.5 to $1 \mathrm{~g} / \mathrm{kg} \mathrm{IV} / 10$ & $\begin{array}{l}\text { Newborn: } 5 \text { to } 10 \mathrm{~mL} / \mathrm{kg} \mathrm{D} 10 \mathrm{~W} \\
\text { Infants and children: } 2 \text { to } 4 \mathrm{~mL} / \mathrm{kg} \text { D25W } \\
\text { Adolescents: } 1 \text { to } 2 \mathrm{~mL} / \mathrm{kg} \mathrm{D50W}\end{array}$ \\
\hline Lidocaine & $\begin{array}{l}\text { Bolus: } 1 \mathrm{mg} / \mathrm{kg} \mathrm{IV} / \mathrm{IO} \\
\text { Infusion: } 20 \text { to } 50 \mu \mathrm{g} / \mathrm{kg} / \mathrm{min}\end{array}$ & \\
\hline Magnesium sulfate & $\begin{array}{l}25 \text { to } 50 \mathrm{mg} / \mathrm{kg} \mathrm{IV/IO} \mathrm{over} 10 \text { to } 20 \text { minutes, faster in torsades de pointes } \\
\text { Maximum dose } 2 \mathrm{~g}\end{array}$ & \\
\hline Sodium bicarbonate & $1 \mathrm{mEq} / \mathrm{kg}$ per dose IV/IO slowly & After adequate ventilation \\
\hline
\end{tabular}

ECG, electrocardiography; IV, intravenous; IO, intraosseous; ET, endotracheal; D10W, 10\% dextrose; D25W, 25\% dextrose; D50W, 50\% dextrose. 


\section{Amiodarone}

Amiodarone delays conduction in the AV node, prolongs the refractory period and OT interval, and slows ventricular conduction. However, amiodarone should be infused as slowly as the patient's condition allows, and their blood pressure should be monitored. The appropriate infusion rate is relatively slow if there is a pulse, and is relatively fast in cases of cardiac arrest or VF. Hypotension can develop due to vasodilation during the administration, and its magnitude is related to the administration rate. This effect is less frequent when amiodarone is administered as a liquid form. ${ }^{20} \mathrm{An}$ electrocardiogram (ECG) should be used to monitor for administration-related complications, such as bradycardia, AV block, and torsades de pointes. Special care should be taken during the coadministration of other medications that can prolong the $\mathrm{OT}$ interval. The half-life of amiodarone can reach 40 days, so any related adverse effect(s) may last a prolonged duration.

\section{Atropine}

As a parasympathetolytic agent, atropine increases cardiac rhythm and AV conduction. Atropine is administered as an IV or intraosseous (I0) infusion, with no minimum dose, in pediatric cases with a risk of severe bradycardia during emergency endotracheal intubation. However, routine atropine administration is not recommended for infants and children if emergency endotracheal intubation is necessary. ${ }^{21-23}$ Large doses of atropine should be administered in cases of nerve gas poisoning or organophosphate poisoning. ${ }^{24}$

\section{Calcium}

The routine administration of calcium during cardiac arrest does not improve the patient's prognosis, and routine administration is not recommended as life support for patients who are in asystole. ${ }^{3,25,26}$ Calcium is used to treat proven hypocalcemia or hyperkalemia, especially in patients with hemodynamic dysfunction. A decrease in the levels of ionized calcium is relatively common in severely ill children, and especially in children with sepsis. Calcium should be considered for treating hypermagnesemia or overdose with a calcium channel blocker. The most common formation of calcium for children is 10\% calcium chloride, as it has a higher bioavailability than calcium gluconate, and this solution should be infused through a central vein due to the risk of peripheral vein injury. ${ }^{27,28}$ An IV infusion of calcium should be administered over 10 to 20 seconds for patients in cardiac arrest and over 5 to 10 minutes for patients with a perfusing rhythm.

\section{Epinephrine}

Epinephrine is an intrinsic catecholamine that strongly stimulates the alpha and beta adrenergic receptors of the sympathetic nerves.
Epinephrine's most significant pharmacological action during cardiac arrest is vasoconstriction caused by activation of alpha adrenergic receptors. This increases the aortic diastolic pressure and the perfusion pressure in the coronary artery, which is a significant determinant of successful CPR. ${ }^{29,30}$ During compressions, the increased perfusion pressure in the coronary artery increases the oxygen supply to the heart. Epinephrine also improves the rate of successful defibrillation by increasing the VF amplitude and myocardial contraction, which stimulates spontaneous contraction.

The most common rhythms during pediatric cardiac arrest are asystole and bradycardia, and epinephrine can provide a perfusing rhythm in these patients. The epinephrine can be administered using an IV/IO infusion, or through the ETT in pediatric patients with symptomatic bradycardia who do not respond to effective assisted ventilation or oxygen supply. However, it is important to monitor the oxygen supply and circulation, because catecholamine activity can be reduced by acidosis or hypoxia. If the initial dose of epinephrine is not effective, it should be repeatedly administered every 3 to 5 minutes during CPR.

Although epinephrine can be absorbed when it is administered using an ET, the absorbed amount and serum concentration cannot be predicted. Therefore, a continuous IV infusion of epinephrine can be helpful once ROSC is achieved. Epinephrine's hemodynamic effects are related to its dosage, with low doses $(<0.3 \mu \mathrm{g} / \mathrm{kg} / \mathrm{min})$ prominently resulting in beta adrenergic activity and higher doses ( $>0.3 \mu \mathrm{g} / \mathrm{kg} / \mathrm{min}$ ) predominantly causing vasoconstriction due to both beta and alpha adrenergic activities. It is preferable to administer epinephrine via the central circulation, as extravasation of epinephrine can lead to local ischemia, tissue damage, and necrosis. Similar to other catecholamines, epinephrine is inactivated in alkali solutions and should not be mixed with sodium bicarbonate. Epinephrine can be administered during CPR for infants and children who are in cardiac arrest, although there is insufficient evidence regarding the effects of other vasopressors. ${ }^{31-34}$

\section{Glucose}

Infants have low stored levels of glucose, and a high demand for glucose. Furthermore, infants can readily develop hypoglycemia if they have a condition that requires an increased energy supply (e.g., shock). Therefore, glucose levels should be closely monitored using a rapid bedside test in cases of coma, shock, or respiratory failure. Once hypoglycemia has been confirmed, it should be treated using a glucose-containing fluid..$^{35}$ Two to four milliliters of $25 \%$ glucose solution $(250 \mathrm{mg} / \mathrm{mL}$ ) per kilogram provides 0.5 to $1.0 \mathrm{~g} / \mathrm{kg}$ of glucose, and 5 to $10 \mathrm{~mL}$ of a $10 \%$ glucose solution (100 $\mathrm{mg} / \mathrm{mL}$ ) also provides a similar amount of glucose. It is preferable to treat hypoglycemia using a continuous infusion of a glucose 
solution, as osmotic diuresis can be caused by a sudden increase in the plasma oncotic pressure after a single administration of a hypertonic glucose solution. The current recommendation is to maintain euglycemia during the CPR and to prevent hypoglycemia after the CPR, as there are no data regarding whether hyperglycemia is advantageous or harmful after cardiac arrest.

\section{Lidocaine}

Lidocaine reduces myocardial automaticity and prevents ventricular arrhythmia. But it can depress the myocardium, and reduces circulation, causing drowsiness, disorientation, muscle twitching, and seizure. Amiodarone and lidocaine can be used in infants and children with VF and pulseless VT that does not respond to defibrilaltion. ${ }^{22,36,37}$ Nevertheless, there is a significant possibility of adverse effect(s) in cases with a low cardiac output, abnormal hepatic function, or abnormal renal function. ${ }^{38,39}$

\section{Magnesium}

Magnesium is only administered to patients with proven hypomagnesemia and torsade de pointes. ${ }^{40-42} \mathrm{~A}$ rapid IV infusion (for a few minutes) of magnesium sulfate is recommended for torsade de pointes, regardless of its cause. Magnesium causes vasodilation, and hypotension can develop when it is rapidly infused.

\section{Sodium bicarbonate}

In most studies, the routine administration of sodium bicarbonate has not improved the post-arrest prognosis. ${ }^{43,44}$ Adequate ventilation, oxygen supply, and effective recovery of systemic perfusion (to correct tissue ischemia) should be the primary concerns in pediatric cardiac arrest, because respiratory failure is an important cause in these cases. Once effective ventilation has been confirmed, and epinephrine with compressions has been started to maximize circulation, the administration of sodium bicarbonate can be considered in cases of a prolonged cardiac arrest. Sodium bicarbonate is also recommended for patients with symptomatic hyperkalemia, hypermagnesemia, and overdose with tricyclic antidepressants or other sodium channel blockers.

If indicated, sodium bicarbonate is administered as an IV or IO infusion, and a diluted solution can be used to prevent increased oncotic pressure in neonates, although there is no evidence that a diluted solution is beneficial in infants or children. The appropriate dose of sodium bicarbonate can be determined using blood gas analysis. Because catecholamines are inactivated by sodium bicarbonate, and calcium forms a precipitate when it is mixed with sodium bicarbonate, 5 to $10 \mathrm{~mL}$ of normal saline should be used to flush the IV line after administering sodium bicarbonate.

\section{Vasopressin}

Vasopressin is an intrinsic hormone that activates a specific receptor and mediates systemic vasoconstriction or water reabsorption in renal tubules. There is insufficient data to determine whether the routine use of vasopressin can be recommended in cases of pediatric cardiac arrest. Vasopressin or terlipressin (a long-acting drug) can be effective in children or adults who have failed standard treatment for cardiac arrest. ${ }^{45-47}$

\section{TREATMENT FOR PULSELESS ARREST}

If a child is unresponsive and breathless, the responder should immediately start high-quality CPR, supply oxygen (if possible), and ask someone to bring a defibrillator. An ECG monitor or automated external defibrillator (AED) electrodes should be attached as soon as possible. Cardiac rhythm is monitored using an ECG monitor during CPR for children, although an AED will automatically notify the rescuer if the patient has a shockable rhythm (VF or pulseless VT) or a non-shockable rhythm (asystole or pulseless electrical activity [PEA]). Temporarily interrupting the compressions may be necessary to check the rhythm. Asystole or wide QRS bradycardia is the most common rhythms during asphyxial cardiac arrest. Although VF or PEA does not frequently occur in infants or children, there is a high probability of VF-induced cardiac arrest in cases of sudden witnessed cardiac arrest among older children (Fig. 1).

\section{Non-shockable rhythm (asystole/PEA)}

The definition of PEA is the presence of organized electrical activity, such as a slow and wide QRS, without a palpable pulse. There can be a normal heart rate without a pulse and with poor tissue perfusion during the early stage of suddenly impaired cardiac output. This condition is more reversible than asystole and used to be known as electromechanical dissociation.

Minimize any interruption in the compressions and continue CPR. The second rescuer should establish an IV or IO line and administer epinephrine at $0.01 \mathrm{mg} / \mathrm{kg}(0.1 \mathrm{~mL} / \mathrm{kg}$ in a 1:10,000 solution) during the CPR, and the same dose should be administered every 3 to 5 minutes. High-dose epinephrine does not improve the survival rate, and can cause harm, although it may be considered in exceptional cases, such as cases of overdose with beta blockers. 32,48

If an advanced airway has been placed, the first rescuer should perform constant compressions at a rate of $\geq 100$ to 120 per minute, and the second rescuer should provide breaths every 6 seconds (approximately 10 per minute). The rescuer(s) who are performing the compressions should switch approximately every 2 minutes, while minimizing the interruption, to provide optimal compression 


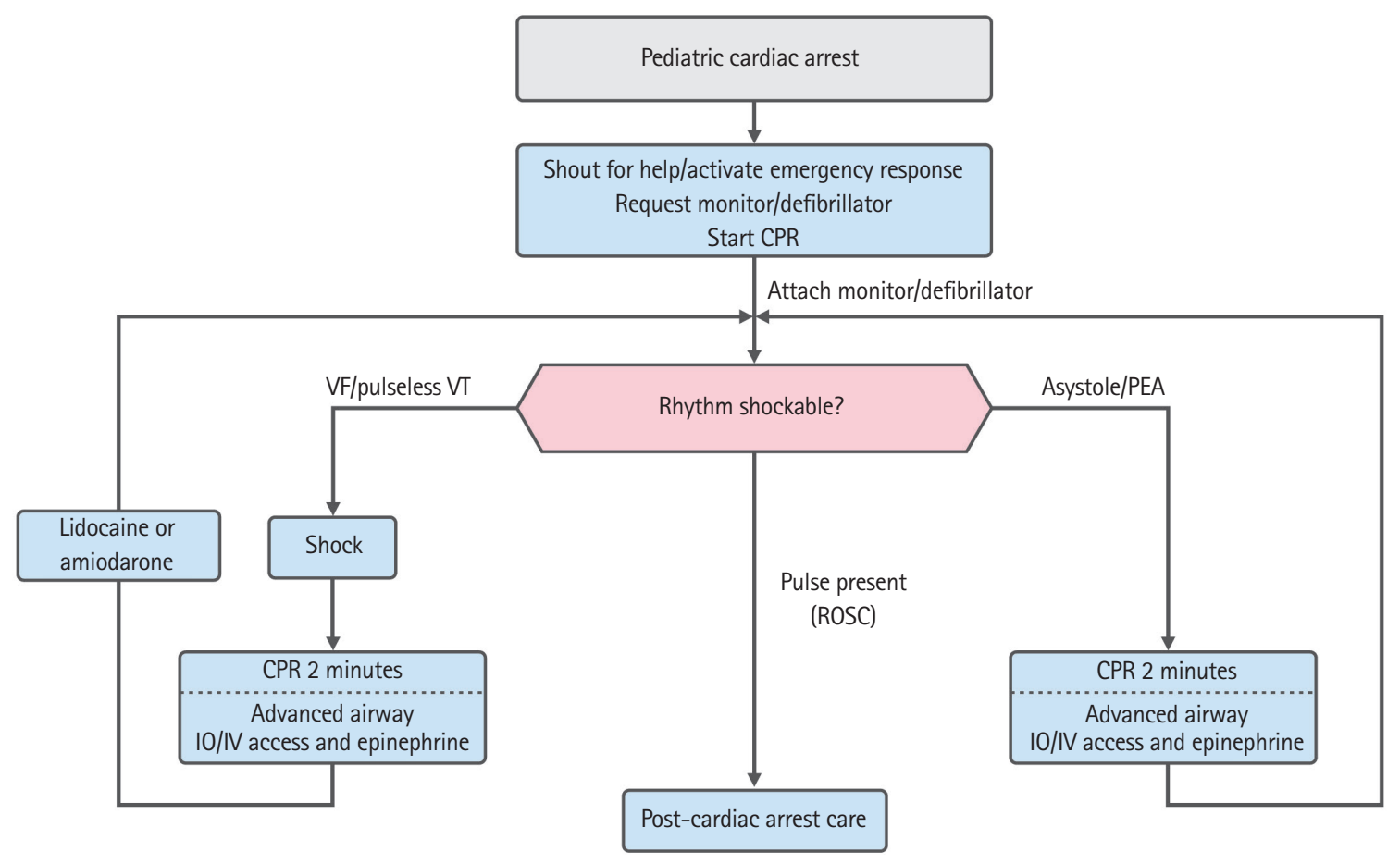

Fig. 1. Algorithm of pediatric cardiac arrest. CPR, cardiopulmonary resuscitation; VF, ventricular fibrillation; VT, ventricular tachycardia; PEA, pulseless electrical activity; IO, intraosseous; IV, intravenous; ROSC, return of spontaneous circulation.

quality and rate, and to avoid compression-induced fatigue. During this period, the rhythm should be monitored while minimizing any interruption of the compressions. If the rhythm is non-shockable, CPR should be continued with epinephrine administration until there is evidence of ROSC or a decision is made to cease CPR. If the rhythm changes to a shockable rhythm, immediate compressions and defibrillation should always be performed, and the rhythm should be rechecked after 2 minutes of CPR. The period between stopping or restarting the compressions and the defibrillation should be minimized. Find reversible cause(s) and correct them.

\section{Shockable rhythm (VF/pulseless VT)}

Defibrillation is the most important treatment for $\mathrm{VF}$, and provides an overall survival rate of approximately $17 \%$ to $20 \% .^{49}$ The resulting survival rate is higher for primary VF, compared to second-

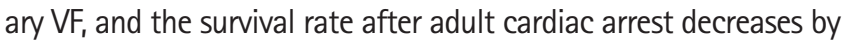
7\% to 10\% for every 1-minute delay in starting CPR and defibrillation..$^{50}$ The survival rate is highest when high-quality CPR is performed with minimal interruptions during the early stage of cardiac arrest. The output of defibrillation is better when the rescuer minimizes the time between the compressions and defibrillation.

\section{DEFIBRILLATORS}

As AEDs can detect the pediatric heart rhythm, they should be installed in facilities that treat children with a risk of arrhythmia or cardiac arrest. The ideal defibrillator can adjust the energy dose for children.

\section{Electrode size}

A manual defibrillator typically has different sizes of electrodes for adults and children, and some manual defibrillators have self-adhesive electrodes. In pediatric cases, the largest appropriate electrode should be selected based on the patient's chest size. The electrodes should not contact each other, and the space between the two electrodes should $\geq 3 \mathrm{~cm}$. Self-adhesive electrodes should be completely attached to the patient's chest by firmly pressing them onto the chest. The adult size of electrodes $(8$ to $10 \mathrm{~cm})$ is used for children who are $\geq 1$ year old or weigh $\geq 10 \mathrm{~kg}$, and the pediatric size is used for infants who are $<1$ year old or weigh $<10 \mathrm{~kg}$.

\section{Interface}

Self-adhesive electrodes have pre-applied electrode gel on the interface that should be placed on the patient's chest. However, electrode gel must be applied for manual electrodes. Normal saline, ultrasound gel, or alcohol are not appropriate replacements 
for electrode gel.

\section{Electrode placement}

The manufacture's recommendations should be followed when placing self-adhesive electrodes of an AED or monitor/defibrillator. Manual electrodes are placed at the apex (at the left lower rib, lateral to the left nipple) and the right upper quadrant of the chest, which locates the heart between the electrodes. The electrodes must be firmly applied to maintain a strong contact, and there is no benefit to placing the electrodes on the anterior and posterior sides of the patient's trunk.

\section{Energy dose}

The lowest energy dose for effective defibrillation and the upper limit for safe defibrillation in infants or children are unknown. The first recommended energy dose is 2 to $4 \mathrm{~J} / \mathrm{kg}$ for monophasic or biphasic defibrillators if the infant or child exhibits VF or pulseless $V T$. The second recommended dose is $4 \mathrm{~J} / \mathrm{kg}$, and any subsequent dose should never exceed the maximum adult dose. ${ }^{50,51}$ If there is no exact energy dose meter on the defibrillator, use the next highest energy on the energy selector when escalating the dose. ${ }^{52-54}$

\section{AEDs}

VF can be accurately detected by most AEDs in children of all ages. If the AED does not have an energy attenuating device, a manual defibrillator is preferred for children who are $<1$ year old. An AED with an energy attenuating device can be used unless a manual defibrillator is available. If both an AED with an energy attenuating device and a manual defibrillator are unavailable, an AED without an energy attenuating device can be used in children.

\section{Integrating defibrillation and CPR}

CPR should be performed until the defibrillator is prepared and defibrillation is feasible, and the compressions should be re-started immediately after the defibrillation. It is ideal to only interrupt the compressions for checking cardiac rhythm, performing defibrillation, and breathing before placing an advanced airway. Once the rhythm has been evaluated, start and continue the compressions until the defibrillator is charged, even in cases with a shockable rhythm. The first defibrillation (2 to $4 \mathrm{~J} / \mathrm{kg}$ ) should be started as soon as possible, and CPR with compressions should be immediately re-started after the defibrillation. It is very important to minimize the interval between starting or stopping the compressions and the defibrillation. Continue CPR for approximately 2 minutes, although this sequence may be changed based on an expert's opinion if the environment can facilitate continuous invasive monitoring (e.g., in a hospital). An IV or IO line can be established if there are enough rescuers. Rhythm should be checked after 2 minutes of CPR, and the defibrillator should be charged at $4 \mathrm{~J} / \mathrm{kg}$. If a shockable rhythm persists, defibrillation should be applied at 4 $\mathrm{J} / \mathrm{kg}$, and the algorithm for asystole/PEA should be followed if a non-shockable rhythm is observed. Resume the compressions immediately after the second defibrillation, and continue CPR for approximately 2 minutes. Epinephrine should be administered at 0.01 $\mathrm{mg} / \mathrm{kg}(0.1 \mathrm{~mL} / \mathrm{kg}$ in a 1:10,000 solution) every 3 to 5 minutes during the CPR. If there is a third rescuer, epinephrine should be prepared before checking the rhythm and administered as soon as possible. The rescuer who is in charge of the defibrillator should prepare the third defibrillator charge before checking the ECG rhythm ( $>4 \mathrm{~J} / \mathrm{kg}$ and $<10 \mathrm{~J} / \mathrm{kg}$ or the maximum adult dose). If there is a shockable rhythm, an additional defibrillation should be administered ( $>4 \mathrm{~J} / \mathrm{kg}$ and $<10 \mathrm{~J} / \mathrm{kg}$ or the maximum adult dose), and CPR should be immediately resumed. If the defibrillation is unsuccessful, amiodarone or lidocaine should be administered while continuing the CPR. The algorithm for pulseless cardiac arrest is always followed if there is a non-shockable rhythm. If an advanced airway is placed, one rescuer should continue compressions at a rate of $\geq 100$ to 120 per minute, and the second rescuer should perform breathing every 6 seconds ( 10 per minute). If there are two or more rescuers, they should switch every 2 minutes to prevent compression-induced fatigue and to maintain adequate compression rate and quality. If there is an organized rhythm at 2 minutes after the defibrillation, check the pulse to determine whether it is a perfusing rhythm. ROSC is predicted if the $\mathrm{ETCO}_{2}$ rapidly increases during the compressions or the monitored arterial waveform increases. If both ROSC and a pulse are achieved, postCPR management can be started. However, if VF re-develops after successful defibrillation, CPR should be re-started and defibrillations should be attempted with the dose which achieved successful defibrillation. Find and correct any other reversible causes.

\section{MANAGEMENT OF TORSADE DE POINTES}

Torsade de pointes is polymorphic VT and is associated with a prolonged QT interval. A prolonged QT interval can develop due to congenital conditions or drug toxicity, and is associated with class 1A antiarrhythmic drugs (procainamide, quinidine, and disopyramide), class III antiarrhythmic drugs (sotalol and amiodarone), tricyclic antidepressants, digoxin, and drug interactions. ${ }^{55,56}$ Torsade de pointes typically progresses to VF or pulseless VT. Therefore, if pulseless cardiac arrest develops, the rescuer must start CPR and perform defibrillation. Regardless of the cause, magnesium (at 25 to $50 \mathrm{mg} / \mathrm{kg}$ to a maximum dose of $2 \mathrm{~g}$ ) should be rapidly administered over a few minutes as an IV infusion. 


\section{POST-CPR MANAGEMENT}

Post-CPR management should begin immediately after ROSC in patients who had shock, respiratory failure, and cardiac arrest. The purposes of post-CPR management are to: (1) maintain brain function, (2) avoid secondary organ damage, (3) correct the cause(s) of the cardiac arrest, and (4) prepare for the next treatment step with an optimal hemodynamic status. Because the patient's condition can deteriorate after a short period of temporary stabilization, the patient should be frequently monitored. Thoroughly determine whether the airway is secure, oxygen is supplied, and ventilation and perfusion are stabilized. Look for evidence of trauma and reevaluate the patient's neurological condition during the examination. Check for any history of allergy, disease, medication, or vaccination, and evaluate the patient's renal and hepatic functions (dysfunction can indirectly affect the patient's prognosis).

\section{Management of the respiratory system}

After children have received CPR, oxygen should be supplied until adequate oxygenation and proper oxygen carrying capacity is achieved, as measured using pulse oximetry or direct arterial blood gas analysis. High-dose oxygen should be administered if there are symptoms of significant respiratory distress (e.g., anxiety, breathing impairment, cyanosis, or hypoxemia), and endotracheal intubation with mechanical ventilation can be performed. If the intubated patient experiences a sudden deterioration, consider the possibility of displacement or obstruction of the ETT, pneumothorax, or mechanical errors. Analgesics or sedatives can be used for anxious patients if these factors are confirmed to be absent. However, careful attention is warranted, as seizures can be masked by the use of a neuromuscular blocker.

A target arterial $\mathrm{CO}_{2}$ partial pressure can be established and maintained based on the patient's specific condition after ROSC is achieved. There is no evidence that hypercapnia or hypocapnia are more beneficial than eucapnia for improving the patient's survival rate and quality of life..$^{57,58}$ Oxygen should be supplied to provide proper oxygenation for intubated patients, and the respiratory rate should be maintained at 30 to 40 per minute for infants and 20 to 30 per minute for children. A sufficient tidal volume will cause the chest to visibly rise. Once mechanical ventilation is started, the tidal volume should be maintained at $6 \mathrm{~mL} / \mathrm{kg}$, which should cause the chest to visibly rise and yield respiratory sounds at the periphery of the lung that can be detected using auscultation. A value of approximately 3 to $6 \mathrm{cmH}_{2} \mathrm{O}$ should be used for positive end-expiratory pressure, although a higher value can be used if the functional residual capacity is reduced and the lung has collapsed.

Arterial blood gas analysis should be performed at 10 to $15 \mathrm{~min}$ - utes after early mechanical ventilation, and it is recommended that normal arterial oxygen partial pressure be maintained unless there is a specific reason for deviation. ${ }^{57,59,60}$ Cardiac anomalies in children should be evaluated via echocardiography immediately after $\mathrm{CPR}$, as the proper oxygen saturation can vary based on the patient's hemodynamic status and congenital heart disease(s). Nasogastric or orogastric tube insertion is needed, as gastric inflation can cause discomfort and ventilation impairment.

\section{Cardiovascular management}

Because circulatory failure can develop after recovery from cardiac arrest, continuous or frequent evaluation of the cardiovascular system should be performed to rapidly detect any decreased cardiac output or the development of shock. Inadequate tissue perfusion can result in a prolonged capillary refill time, a reduced or absent peripheral pulse, a change in consciousness, cold extremities, tachycardia, a decreased urine output, and hypotension. An insufficient administration of fluid after CPR can cause a reduction in the cardiac output or shock that develops secondary to the reduced peripheral vascular resistance and myocardial stunning. ${ }^{61}$

Heart rate, blood pressure, and oxygen saturation should be constantly monitored after $\mathrm{CPR}$, and blood pressure should be monitored using an intra-arterial catheter (if possible) in patients with cardiovascular dysfunction. Because hypotension can frequently occur during the period of ROSC after CPR, and this condition is associated with a poor prognosis, the systolic pressure should be maintained at or above the fifth age-specific percentile, and IV fluids or inotropic agents should be administered. ${ }^{62-64}$ Urine output is a significant indicator of internal organ perfusion, and should be monitored using a urine catheter in patients with hemodynamic dysfunction. The 10 route should be removed once a secure IV line is established.

\section{Drugs to maintain cardiac output}

Myocardial impairment and vascular instability frequently occur after recovery from cardiac arrest. After CPR, systemic and pulmonary vascular resistance usually increase during the early phase, except in cases of septic shock. Cardiovascular function also constantly changes after CPR, as it exhibits a hyperdynamic status during the early phase, which subsides towards a gradual weakening of cardiac function. Therefore, if abnormal cardiovascular function is observed or suspected after CPR, an adequate dose of vasoactive drug(s) should be administered to improve cardiac function and tissue perfusion. The selection and dose of the drug(s) should be based on the individual patient's status, and should be administered using an accurate IV route. 


\section{1) Epinephrine}

Epinephrine is used to treat shock for any reason, which does not respond to fluid administration and exhibits extremely low systemic perfusion. As a strong vasoconstrictor, epinephrine increases systemic vascular resistance and heart rate through its chronotropic activity. Epinephrine can be administered during bradycardia with hemodynamic changes that do not respond to oxygen and mechanical ventilation.

Low-dose epinephrine $(<0.3 \mu \mathrm{g} / \mathrm{kg} / \mathrm{min}$ ) works as a strong inotropic agent and reduces systemic vascular resistance by activating beta adrenergic receptors. If the dose is increased to $>0.3 \mu \mathrm{g} /$ $\mathrm{kg} / \mathrm{min}$, epinephrine exerts both an inotropic effect and increases systemic vascular resistance by activating the vascular alpha adrenergic receptors. As epinephrine's effects vary according to the dose in different patients, the dose must be frequently adjusted to achieve its intended effect. Epinephrine is more effective than dopamine in patients with severe circulatory compromise, and especially in infants. ${ }^{65}$

\section{2) Dopamine}

Dopamine has beta and alpha sympathomimetic effects through a direct dopaminergic effect and an indirect stimulatory effect on norepinephrine secretion. The dose of dopamine must be frequently adjusted when it is used to treat shock with low systemic vascular resistance and no response to fluid administration. Although it barely affects the systemic hemodynamic status at low doses ( 0.5 to $2 \mu \mathrm{g} / \mathrm{kg} / \mathrm{min}$ ), dopamine typically increases the blood flow to the heart and intestine, and increases cardiac output and blood pressure in neonates. ${ }^{66}$ At doses of $>5 \mu \mathrm{g} / \mathrm{kg} / \mathrm{min}$, dopamine induces cardiac beta adrenergic receptor activity, which induces the secretion of norepinephrine from the cardiac sympathetic nerve. However, dopamine's ability to stimulate myocardial and vascular contraction can be reduced in some cases, such as chronic heart failure patients with depletion of myocardial norepinephrine, and infants who are $<1$ month old with incomplete development of the cardiac sympathetic nerve. At doses of $>20 \mu \mathrm{g} /$ $\mathrm{kg} / \mathrm{min}$, dopamine induces excessive vasoconstriction and renovascular dilatation disappears. Therefore, epinephrine or dobutamine are recommended in cases where $>20 \mu \mathrm{g} / \mathrm{kg} / \mathrm{min}$ of dopamine would be needed to increase myocardial contraction. Dopamine is a catecholamine that can be partially inactivated in alkali solutions, and should not be mixed with bicarbonate. ${ }^{67}$

\section{3) Dobutamine}

Dobutamine is a synthetic catecholamine that exerts relatively selective effects on the beta- 1 adrenergic receptor, and has minimal effects on the beta- 2 adrenergic receptor. Therefore, dobutamine is a relatively selective inotrope that can increase myocardial contraction and reduce systemic vascular resistance. ${ }^{68}$ Dobutamine is effective for increasing cardiac output and blood pressure in infants and children. In particular, dobutamine can be used to treat secondary reductions in cardiac output due to decreased myocardial function, such as in the post-cardiac arrest situation. Tachycardia and premature ventricular contractions can occur at high doses of dobutamine.

\section{4) Norepinephrine}

Norepinephrine is a neurotransmitter that is secreted from the sympathetic nerve, and is a strong inotrope that it works on the peripheral alpha and beta sympathetic nerves to induce strong myocardial and peripheral vascular contractions. The alpha sympathomimetic effect is predominant at the standard dose. As norepinephrine is a strong vasoconstrictor, it can be used to treat septic shock that does not respond to fluid infusion and exhibits low systemic vascular resistance, spinal shock, and anaphylaxis. The infusion rate may be adjusted according to the patient's blood pressure and perfusion status.

\section{5) Nitroprusside}

Nitroprusside is a vasodilator that induces the local production of nitric oxide in all blood vessels. At the therapeutic dose, it has no direct effects on myocytes, and increases cardiac output by reducing the resistance of the systemic and pulmonary blood vessels. The combination of nitroprusside and inotropes can be used in patients with severe hypertension or reduced cardiac output due to reduced myocardial function and increased vascular resistance. However, it should not be used if the blood volume is reduced, as it can cause severe hypotension. Nitroprusside is rapidly metabolized and should be constantly infused with a dextrose solution, and should not be mixed with normal saline. Levels of thiocyanate should be monitored in cases with prolonged use, and especially when the infusion rate is $>2 \mu \mathrm{g} / \mathrm{kg} / \mathrm{min}$.

\section{6) Inodilators}

Inodilators, such as amrinone and milrinone, are used for patients with reduced cardiac function or increased resistance of the systemic and pulmonary blood vessels. Similar to vasodilators, inodilators do not increase the myocardial oxygen demand, increase the cardiac output, and have minimal effect on the heart rate. Hypotension is not common if the circulating blood volume is adequate, but can occur due to vasodilation if there is an inadequate circulating blood volume. Therefore, fluid administration may be necessary to counteract vasodilation after drug administration. ${ }^{69}$ 


\section{Nervous system management}

The primary purpose of CPR is to maintain brain function, and care must be taken to prevent secondary damage to the nervous system after CPR. Hyperventilation has a negative effect on the prognosis of the nervous system, as it affects both cardiac function and cerebral perfusion. Short periods of intentional hyperventilation are acceptable in cases with signs of brain herniation, such as a sudden increase in intracranial pressure, mydriasis without a light reflex, bradycardia, or hypertension. Target temperature management can be considered for unconscious infants or children with ROSC after cardiac arrest. The body temperature should not be allowed to drop below $32^{\circ} \mathrm{C}$, or to increase above $37.5^{\circ} \mathrm{C}$, even if target temperature management is not performed. ${ }^{70-75} \mathrm{As}$ fever has a negative effect on the recovery of brain function, it should be actively treated using an antipyretic drug and an external cooling method. Tremors can occur at low temperatures, and can be prevented using a sedative. Neuromuscular blockade can be used if necessary, although it can mask a seizure, and continuous electroencephalogram monitoring can be used to detect seizures. ${ }^{76}$ Although an adequate cooling and rewarming method has not been established, the body temperature should not increase at a rate of $>0.5^{\circ} \mathrm{C}$ every 2 hours, unless there is another reason for rapid rewarming.

\section{Renal system management}

The prerenal condition that is caused by dehydration or inadequate perfusion, and/or ischemic injuries in the kidney(s), can reduce urine output (infants and children: $<1 \mathrm{~mL} / \mathrm{kg} / \mathrm{hr}$, adolescents: $<30 \mathrm{~mL} / \mathrm{hr}$ ). Avoid using drugs with renal toxicity until the patient's renal function has been confirmed, and adjust the dose of drugs that undergo renal excretion.

\section{Gastrointestinal system management}

In cases with no bowel sounds, abdominal distention, or required mechanical ventilation, perform nasogastric or orogastric intubation to prevent or treat gastric inflation. However, nasogastric intubation is prohibited in patients with facial injuries or basal skull fractures, because the tube can enter the cranium.

\section{Factors predicting prognosis}

The survival rate is higher in cases with a pupillary reflex within 24 hours after CPR, compared to that in cases that do not fulfill this criterion, ${ }^{3,77-80}$ and there are reports that a poor prognosis may be predicted by increased levels of neuron-specific enolase and S100 calcium-binding protein $\mathrm{B}^{78,81,82}$ Although there are no established predictors of neurological and survival outcomes in children with ROSC, these outcomes may be predicted by pupillary reflex, neuron- specific enolase and S100 calcium-binding protein B levels. Furthermore, electroencephalogram results within 7 days after cardiac arrest may help predict neurologic outcomes, ${ }_{1}^{76,80}$ but the outcomes cannot be predicted using only electroencephalogram results.

\section{REFERENCES}

1. Kuisma M, Suominen P, Korpela R. Paediatric out-of-hospital cardiac arrests: epidemiology and outcome. Resuscitation 1995;30:141-50.

2. Donoghue A, Nadkarni V, Berg RA, et al. Out-of-hospital pediatric cardiac arrest: an epidemiologic review and assessment of current knowledge. Ann Emerg Med 2005;46:512-22.

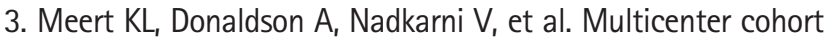
study of in-hospital pediatric cardiac arrest. Pediatr Crit Care Med 2009;10:544-53.

4. Tibballs J, Kinney S. Reduction of hospital mortality and of preventable cardiac arrest and death on introduction of a pediatric medical emergency team. Pediatr Crit Care Med 2009;10:30612.

5. Gausche M, Lewis RJ. Out-of-hospital endotracheal intubation of children. JAMA 2000;283:2790-2.

6. Aufderheide TP, Sigurdsson G, Pirrallo RG, et al. Hyperventilation-induced hypotension during cardiopulmonary resuscitation. Circulation 2004;109:1960-5.

7. Davidovic L, LaCovey D, Pitetti RD. Comparison of 1- versus 2-person bag-valve-mask techniques for manikin ventilation of infants and children. Ann Emerg Med 2005;46:37-42.

8. Daugherty RJ, Nadkarni V, Brenn BR. Endotracheal tube size estimation for children with pathological short stature. Pediatr Emerg Care 2006;22:710-7.

9. Hofer CK, Ganter M, Tucci M, Klaghofer R, Zollinger A. How reliable is length-based determination of body weight and tracheal tube size in the paediatric age group? The Broselow tape reconsidered. Br J Anaesth 2002;88:283-5.

10. Weiss M, Dullenkopf A, Fischer JE, Keller C, Gerber AC; European Paediatric Endotracheal Intubation Study Group. Prospective randomized controlled multi-centre trial of cuffed or uncuffed endotracheal tubes in small children. $\mathrm{Br} J$ Anaesth 2009;103:867-73.

11. Dullenkopf A, Gerber AC, Weiss M. Fit and seal characteristics of a new paediatric tracheal tube with high volume-low pressure polyurethane cuff. Acta Anaesthesiol Scand 2005;49:2327.

12. Salgo B, Schmitz A, Henze G, et al. Evaluation of a new recommendation for improved cuffed tracheal tube size selection in infants and small children. Acta Anaesthesiol Scand 
2006;50:557-61.

13. Duracher C, Schmautz E, Martinon C, Faivre J, Carli P, Orliaguet G. Evaluation of cuffed tracheal tube size predicted using the Khine formula in children. Paediatr Anaesth 2008;18:113-8.

14. Browning DH, Graves SA. Incidence of aspiration with endotracheal tubes in children. J Pediatr 1983;102:582-4.

15. Khine $H H$, Corddry DH, Kettrick RG, et al. Comparison of cuffed and uncuffed endotracheal tubes in young children during general anesthesia. Anesthesiology 1997;86:627-31.

16. Newth CJ, Rachman B, Patel N, Hammer J. The use of cuffed versus uncuffed endotracheal tubes in pediatric intensive care. J Pediatr 2004;144:333-7.

17. Kim JT, Kim HJ, Ahn W, et al. Head rotation, flexion, and extension alter endotracheal tube position in adults and children. Can J Anaesth 2009;56:751-6.

18. Cantineau JP, Merckx $P$, Lambert $Y$, Sorkine $M$, Bertrand $C$, Duvaldestin P. Effect of epinephrine on end-tidal carbon dioxide pressure during prehospital cardiopulmonary resuscitation. Am J Emerg Med 1994;12:267-70.

19. Ornato JP, Shipley JB, Racht EM, et al. Multicenter study of a portable, hand-size, colorimetric end-tidal carbon dioxide detection device. Ann Emerg Med 1992;21:518-23.

20. Somberg JC, Bailin SJ, Haffajee $\mathrm{Cl}$, et al. Intravenous lidocaine versus intravenous amiodarone (in a new aqueous formulation) for incessant ventricular tachycardia. Am J Cardiol 2002;90:8539.

21. Jones P, Peters MJ, Pinto da Costa N, et al. Atropine for critical care intubation in a cohort of 264 children and reduced mortality unrelated to effects on bradycardia. PLoS One 2013; 8:e57478.

22. Jones $P$, Dauger $S$, Denjoy I, et al. The effect of atropine on rhythm and conduction disturbances during 322 critical care intubations. Pediatr Crit Care Med 2013;14:e289-97.

23. Fastle RK, Roback MG. Pediatric rapid sequence intubation: incidence of reflex bradycardia and effects of pretreatment with atropine. Pediatr Emerg Care 2004;20:651-5.

24. Zwiener RJ, Ginsburg CM. Organophosphate and carbamate poisoning in infants and children. Pediatrics 1988;81:121-6.

25. de Mos N, van Litsenburg RR, McCrindle B, Bohn DJ, Parshuram CS. Pediatric in-intensive-care-unit cardiac arrest: incidence, survival, and predictive factors. Crit Care Med 2006;34:120915.

26. Srinivasan V, Morris MC, Helfaer MA, Berg RA, Nadkarni VM; American Heart Association National Registry of CPR Investigators. Calcium use during in-hospital pediatric cardiopulmonary resuscitation: a report from the National Registry of Cardiopulmonary Resuscitation. Pediatrics 2008;121:e1144-
51.

27. Martin TJ, Kang Y, Robertson KM, Virji MA, Marquez JM. Ionization and hemodynamic effects of calcium chloride and calcium gluconate in the absence of hepatic function. Anesthesiology 1990;73:62-5.

28. Broner CW, Stidham GL, Westenkirchner DF, Watson DC. A prospective, randomized, double-blind comparison of calcium chloride and calcium gluconate therapies for hypocalcemia in critically ill children. J Pediatr 1990;117:986-9.

29. Niemann JT, Criley JM, Rosborough JP, Niskanen RA, Alferness C. Predictive indices of successful cardiac resuscitation after prolonged arrest and experimental cardiopulmonary resuscitation. Ann Emerg Med 1985;14:521-8.

30. Sanders AB, Ewy GA, Taft TV. Prognostic and therapeutic importance of the aortic diastolic pressure in resuscitation from cardiac arrest. Crit Care Med 1984;12:871-3.

31. Enright $K$, Turner $C$, Roberts $P$, Cheng N, Browne G. Primary cardiac arrest following sport or exertion in children presenting to an emergency department: chest compressions and early defibrillation can save lives, but is intravenous epinephrine always appropriate? Pediatr Emerg Care 2012;28:336-9.

32. Dieckmann RA, Vardis R. High-dose epinephrine in pediatric out-of-hospital cardiopulmonary arrest. Pediatrics 1995;95:90113.

33. Jacobs IG, Finn JC, Jelinek GA, Oxer HF, Thompson PL. Effect of adrenaline on survival in out-of-hospital cardiac arrest: a randomised double-blind placebo-controlled trial. Resuscitation 2011;82:1138-43.

34. Matamoros M, Rodriguez R, Callejas A, et al. In-hospital pediatric cardiac arrest in Honduras. Pediatr Emerg Care 2015;31:315.

35. Beiser DG, Carr GE, Edelson DP, Peberdy MA, Hoek TL. Derangements in blood glucose following initial resuscitation from inhospital cardiac arrest: a report from the national registry of cardiopulmonary resuscitation. Resuscitation 2009;80:624-30.

36. Valdes SO, Donoghue AJ, Hoyme DB, et al. Outcomes associated with amiodarone and lidocaine in the treatment of in-hospital pediatric cardiac arrest with pulseless ventricular tachycardia or ventricular fibrillation. Resuscitation 2014;85:381-6.

37. Dorian P, Cass D, Schwartz B, Cooper R, Gelaznikas R, Barr A. Amiodarone as compared with lidocaine for shock-resistant ventricular fibrillation. N Engl J Med 2002;346:884-90.

38. Wilson FC, Harpur J, Watson T, Morrow Jl. Adult survivors of severe cerebral hypoxia: case series survey and comparative analysis. NeuroRehabilitation 2003;18:291-8.

39. Thomson PD, Melmon KL, Richardson JA, et al. Lidocaine pharmacokinetics in advanced heart failure, liver disease, and 
renal failure in humans. Ann Intern Med 1973;78:499-508.

40. Allegra J, Lavery $R$, Cody $R$, et al. Magnesium sulfate in the treatment of refractory ventricular fibrillation in the prehospital setting. Resuscitation 2001;49:245-9.

41. Hassan TB, Jagger $C$, Barnett DB. A randomised trial to investigate the efficacy of magnesium sulphate for refractory ventricular fibrillation. Emerg Med J 2002;19:57-62.

42. Thel MC, Armstrong AL, McNulty SE, Califf RM, O'Connor CM. Randomised trial of magnesium in in-hospital cardiac arrest. Duke Internal Medicine Housestaff. Lancet 1997;350:1272-6.

43. Vukmir RB, Katz L; Sodium Bicarbonate Study Group. Sodium bicarbonate improves outcome in prolonged prehospital cardiac arrest. Am J Emerg Med 2006;24:156-61.

44. Lokesh L, Kumar P, Murki S, Narang A. A randomized controlled trial of sodium bicarbonate in neonatal resuscitationeffect on immediate outcome. Resuscitation 2004;60:219-23.

45. Duncan JM, Meaney $P$, Simpson $P$, et al. Vasopressin for inhospital pediatric cardiac arrest: results from the American Heart Association National Registry of Cardiopulmonary Resuscitation. Pediatr Crit Care Med 2009;10:191-5.

46. Mann K, Berg RA, Nadkarni V. Beneficial effects of vasopressin in prolonged pediatric cardiac arrest: a case series. Resuscitation 2002;52:149-56.

47. Matok I, Vardi A, Augarten A, et al. Beneficial effects of terlipressin in prolonged pediatric cardiopulmonary resuscitation: a case series. Crit Care Med 2007;35:1161-4.

48. Perondi MB, Reis AG, Paiva EF, Nadkarni VM, Berg RA. A comparison of high-dose and standard-dose epinephrine in children with cardiac arrest. N Engl J Med 2004;350:1722-30.

49. Berg MD, Samson RA, Meyer RJ, Clark LL, Valenzuela TD, Berg RA. Pediatric defibrillation doses often fail to terminate prolonged out-of-hospital ventricular fibrillation in children. Resuscitation 2005;67:63-7.

50. Rossano JW, Quan L, Kenney MA, Rea TD, Atkins DL. Energy doses for treatment of out-of-hospital pediatric ventricular fibrillation. Resuscitation 2006;70:80-9.

51. Berg RA, Samson RA, Berg MD, et al. Better outcome after pediatric defibrillation dosage than adult dosage in a swine model of pediatric ventricular fibrillation. J Am Coll Cardiol 2005;45:786-9.

52. Rodriguez-Nunez A, Lopez-Herce J, del Castillo J, Bellon JM; Iberian-American Paediatric Cardiac Arrest Study Network RIBEPCI. Shockable rhythms and defibrillation during in-hospital pediatric cardiac arrest. Resuscitation 2014;85:387-91.

53. Gutgesell HP, Tacker WA, Geddes LA, Davis S, Lie JT, McNamara DG. Energy dose for ventricular defibrillation of children. Pediatrics 1976;58:898-901.
54. Meaney PA, Nadkarni VM, Atkins DL, et al. Effect of defibrillation energy dose during in-hospital pediatric cardiac arrest. Pediatrics 2011;127:e16-23.

55. van Haarst $A D$, van 't Klooster GA, van Gerven JM, et al. The influence of cisapride and clarithromycin on QT intervals in healthy volunteers. Clin Pharmacol Ther 1998;64:542-6.

56. Ray WA, Murray KT, Meredith S, Narasimhulu SS, Hall K, Stein $\mathrm{CM}$. Oral erythromycin and the risk of sudden death from cardiac causes. N Engl J Med 2004;351:1089-96.

57. Bennett $K S$, Clark $A E$, Meert $K L$, et al. Early oxygenation and ventilation measurements after pediatric cardiac arrest: lack of association with outcome. Crit Care Med 2013;41:153442.

58. Del Castillo J, Lopez-Herce J, Matamoros M, et al. Hyperoxia, hypocapnia and hypercapnia as outcome factors after cardiac arrest in children. Resuscitation 2012;83:1456-61.

59. Ferguson LP, Durward A, Tibby SM. Relationship between arterial partial oxygen pressure after resuscitation from cardiac arrest and mortality in children. Circulation 2012;126:33542.

60. Guerra-Wallace MM, Casey FL 3rd, Bell MJ, Fink EL, Hickey RW. Hyperoxia and hypoxia in children resuscitated from cardiac arrest. Pediatr Crit Care Med 2013;14:e143-8.

61. Topjian AA, French B, Sutton RM, et al. Early postresuscitation hypotension is associated with increased mortality following pediatric cardiac arrest. Crit Care Med 2014;42:1518-23.

62. Lin YR, Li CJ, Wu TK, et al. Post-resuscitative clinical features in the first hour after achieving sustained ROSC predict the duration of survival in children with non-traumatic out-ofhospital cardiac arrest. Resuscitation 2010;81:410-7.

63. Lin YR, Wu HP, Chen WL, et al. Predictors of survival and neurologic outcomes in children with traumatic out-of-hospital cardiac arrest during the early postresuscitative period. J Trauma Acute Care Surg 2013;75:439-47.

64. Young MN, Hollenbeck RD, Pollock JS, et al. Higher achieved mean arterial pressure during therapeutic hypothermia is not associated with neurologically intact survival following cardiac arrest. Resuscitation 2015;88:158-64.

65. Zaritsky A, Chernow B. Use of catecholamines in pediatrics. J Pediatr 1984;105:341-50.

66. Bellomo R, Chapman M, Finfer S, Hickling K, Myburgh J. Lowdose dopamine in patients with early renal dysfunction: a placebo-controlled randomised trial. Australian and New Zealand Intensive Care Society (ANZICS) Clinical Trials Group. Lancet 2000;356:2139-43.

67. Ushay HM, Notterman DA. Pharmacology of pediatric resuscitation. Pediatr Clin North Am 1997;44:207-33. 
68. Ruffolo RR Jr, Spradlin TA, Pollock GD, Waddell JE, Murphy PJ. Alpha and beta adrenergic effects of the stereoisomers of dobutamine. J Pharmacol Exp Ther 1981;219:447-52.

69. Barton P, Garcia J, Kouatli A, et al. Hemodynamic effects of i.v. milrinone lactate in pediatric patients with septic shock: a prospective, double-blinded, randomized, placebo-controlled, interventional study. Chest 1996;109:1302-12.

70. Doherty DR, Parshuram CS, Gaboury I, et al. Hypothermia therapy after pediatric cardiac arrest. Circulation 2009;119:1492500.

71. Fink EL, Clark RS, Kochanek PM, Bell MJ, Watson RS. A tertiary care center's experience with therapeutic hypothermia after pediatric cardiac arrest. Pediatr Crit Care Med 2010;11:6674.

72. Laptook A, Tyson J, Shankaran S, et al. Elevated temperature after hypoxic-ischemic encephalopathy: risk factor for adverse outcomes. Pediatrics 2008;122:491-9.

73. Lin JJ, Hsia SH, Wang HS, Chiang MC, Lin KL. Therapeutic hypothermia associated with increased survival after resuscitation in children. Pediatr Neurol 2013;48:285-90.

74. Moler FW, Silverstein FS, Holubkov R, et al. Therapeutic hypothermia after out-of-hospital cardiac arrest in children. N Engl J Med 2015;372:1898-908.

75. Scholefield BR, Morris KP, Duncan HP, et al. Evolution, safety and efficacy of targeted temperature management after pediatric cardiac arrest. Resuscitation 2015;92:19-25.
76. Kessler SK, Topjian AA, Gutierrez-Colina AM, et al. Short-term outcome prediction by electroencephalographic features in children treated with therapeutic hypothermia after cardiac arrest. Neurocrit Care 2011;14:37-43.

77. Abend NS, Topjian AA, Kessler SK, et al. Outcome prediction by motor and pupillary responses in children treated with therapeutic hypothermia after cardiac arrest. Pediatr Crit Care Med 2012;13:32-8.

78. Fink EL, Berger RP, Clark RS, et al. Serum biomarkers of brain injury to classify outcome after pediatric cardiac arrest. Crit Care Med 2014;42:664-74.

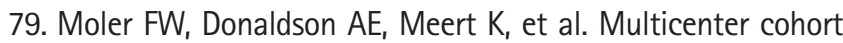
study of out-of-hospital pediatric cardiac arrest. Crit Care Med 2011;39:141-9.

80. Nishisaki A, Sullivan J 3rd, Steger B, et al. Retrospective analysis of the prognostic value of electroencephalography patterns obtained in pediatric in-hospital cardiac arrest survivors during three years. Pediatr Crit Care Med 2007;8:10-7.

81. Pfeifer R, Borner A, Krack A, Sigusch HH, Surber R, Figulla HR. Outcome after cardiac arrest: predictive values and limitations of the neuroproteins neuron-specific enolase and protein S-100 and the Glasgow Coma Scale. Resuscitation 2005;65:49-55.

82. Topjian AA, Lin R, Morris MC, et al. Neuron-specific enolase and $\mathrm{S}-100 \mathrm{~B}$ are associated with neurologic outcome after pediatric cardiac arrest. Pediatr Crit Care Med 2009;10:479-90. 